\title{
DETERMINATION OF STRESS STATE IN COAL SEAM BASED ON INVERSE PROBLEM SOLUTION USING ACOUSTIC SOUNDING DATA
}

\author{
Mels K. KUDAIBERGENOV ${ }^{1 *}$, Kazizat T. ISKAKOV ${ }^{2}$, \\ Bakytzhan S. KUDAIBERGENOVA ${ }^{1}$ \\ ${ }^{1}$ Kazakh Humanitarian Juridical Innovative University, st. Mangilik el 11, VKO Semey, Kazakhstan \\ ${ }^{2}$ L.N. Gumilyov Eurasian National University, korpus 2, st. Pushkina 11, 010008 Astana, Kazakhstan
}

\begin{abstract}
The paper presents an algorithm for calculating the horizontal, vertical and tangential stresses in a horizontal coal seam lying between galleries. These stresses are expressed in terms of the Airy function, which satisfies a homogeneous biharmonic equation. For its numerical solution it is necessary to set boundary conditions. Practical limitations do not allow us to determine the tangential stresses on horizontal boundaries of the coal seam. Calculations of stresses are proposed to be carried out in two steps. The first step is to solve the inverse problem for the biharmonic equation to find unknown tangential stresses on horizontal boundaries of the coal seam. The inverse problem is solved by minimizing the residual functional. Its strong convexity is proved, which implies the existence and uniqueness of the solution of the inverse problem. The second step is to solve the boundary value problem for the biharmonic equation to calculate stresses in the coal seam. The result of a numerical experiment is presented.
\end{abstract}

Keywords: coal seam, stress, plane problem of the elasticity theory, biharmonic equation, inverse problem

\section{INTRODUCTION}

During the development of mineral deposits, the natural balance of the rock mass is disturbed. The stress level in the unspringing zones of concentration may exceed the critical (Baklashov 2005; Jaeger et al. 2007). In combine coal mining, this situation is particularly likely, since the slaughter speed reaches several tens of meters per a day

\footnotetext{
*Corresponding author: melskk@mail.ru (M. Kudaibergenov)
}

doi: $10.37190 / \mathrm{msc} 192611$ 
(Zakharov et al. 2016). Monitoring of the state of the rock massifs in mines is controlled by geomonitoring systems (Zakharov 2002), information is interpreted also by the traditional methods (Luxbacher et al. 2008) and with involving geomechanical modeling (Djadkov et al. 1997; Nazarov et al. 2011; 2013a; 2013b; Nazarova et al. $2014 ; 2015 ; 2016)$. In modeling, for tested object, for example, it is required to specify its structure, physical properties, boundary conditions (external stresses).

The target of the lasts in the study of the stress-strain state of coal seams encounters difficulties due to the uncertainty of the contact properties of the coal seam with the host rocks (Bulat et al. 2008). For example, for contacts of a coal seam with enclosing rocks it is quite typical the presence of thin intermediate layers of carbonaceous rocks or high-ash clay coals (Mountain Encyclopedia 1991; Dorokhov 1997; Mironov 1988), whose mechanical properties are significantly different from those for coal and even more so for the host rock. These properties cannot be determined using direct measurements (Turchaninov et al. 1989), therefore there is using various indirect heuristic methods (Shkuratnik et al. 2012), however, it is difficult or impossible to say how close they are to the truth in each specific case.

When simulating geomechanical fields in the area that includes the coal seam and the host rock, it is necessary to set the conditions for gluing the corresponding stresses at the contact point "coal seam-host rock". If due to vertical stresses at horizontal boundaries there are no particular difficulties in their assignment, then, because of the various properties of the host surrounding and coal for tangential stresses, the uncertainty arises.

Obviously, the result of modeling of geomechanical fields and making decisions based on their analysis directly depend on the accuracy of determining the tangential stresses at the horizontal boundaries of the coal seam. In practice, as a rule, the following method is used (Farmer, 1985): they set the stress distribution from the solution of an elastic task in the host surrounding, and then correct the boundary conditions according to the field measurements of convergence of the roof of the rock of the developed space. Note that with this approach, considerable uncertainty remains in the accuracy of specifying the tangential stresses at the boundary "coal seam-host rock".

The article presents an algorithm for calculating horizontal, vertical and tangential stresses in a coal seam. There was suggestion to search these stresses in two steps. At the first step, the inverse problem is solving for the biharmonic equation in the search for unknown boundary conditions - tangential stresses at the horizontal boundaries of the coal seam. Additional information for solving the inverse problem is the distribution of average stresses in a certain neighborhood of the middle of the seam, which can be determined by the method proposed in (Nazarova et al. 2016). The point of this method lies in the fact that this work shows an empirical dependence between the velocity of propagation of elastic waves in a coal seam and the mean normal stress. At the second step, there is solving the boundary value problem for the biharmonic equa- 
tion, which allows to calculate all the necessary stress values. The inverse problem is solved by minimizing the discrepancy functional. Under some conditions, its shown the strong convexity, this entails the existence and uniqueness of the solution of the inverse problem, is solved in the first step.

\section{PROBLEM STATEMENT}

Consider a model of a coal seam located between two drifts (see Fig. 1). Since the coal seam length is large compared with its thickness and width, we believe that the plane strain can be applicable (see, for example, Aleksandrov, Potapov 1990; Bezukhov 1968; Kiselyov 1976; Nowacki 1970; Samul' 1982).
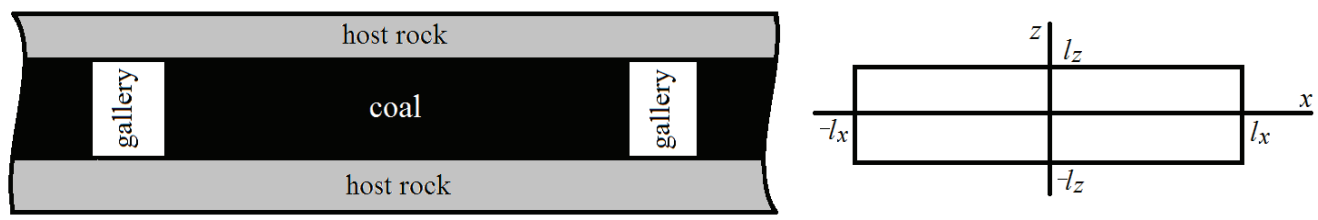

Fig. 1. Model of coal seam, the coordinate system adopted in the work

Thus, the stress state in a coal seam is described by the values $\sigma_{x x}, \sigma_{z z}, \sigma_{x z}-$ horizontal, vertical and tangential stresses. These values satisfy the equilibrium equations

$$
\frac{\partial \sigma_{x x}}{\partial x}+\frac{\partial \sigma_{x z}}{\partial z}=0, \quad \frac{\partial \sigma_{x z}}{\partial x}+\frac{\partial \sigma_{z z}}{\partial z}=0 .
$$

We also consider that there is Saint-Venant strain compatibility condition

$$
\frac{\partial^{2} \varepsilon_{x}}{\partial z^{2}}+\frac{\partial^{2} \varepsilon_{x z}}{\partial x^{2}}=\frac{\partial^{2} \gamma_{x z}}{\partial x \partial z}
$$

and Hooke's law

$$
\varepsilon_{x}=\frac{1}{E^{\prime}}\left(\sigma_{x x}-v^{\prime} \sigma_{z z}\right), \quad \varepsilon_{z}=\frac{1}{E^{\prime}}\left(\sigma_{z z}-v^{\prime} \sigma_{x x}\right), \quad \gamma_{x z}=\frac{2\left(1+v^{\prime}\right)}{E^{\prime}} \sigma_{x z},
$$

where $E^{\prime}=\frac{E}{1-v^{2}}$ and $v^{\prime}=\frac{v}{1-v^{2}}$ are Young modulus and Poisson ratio for the plane problem of elasticity theory.

It is known (see, for example, Aleksandrov, Potapov 1990; Bezukhov 1968; Kiselyov 1976; Nowacki 1970; Samul' 1982), the consequences of relations (1)-(3) are representations 


$$
\sigma_{x x}=\frac{\partial^{2} \varphi}{\partial z^{2}}, \quad \sigma_{z z}=\frac{\partial^{2} \varphi}{\partial x^{2}}, \quad \sigma_{x z}=\frac{\partial^{2} \varphi}{\partial x \partial z},
$$

where $\varphi$ is the Airy function that satisfies the biharmonic equation

$$
\Delta^{2} \varphi=0 .
$$

For the solution of equation (5), and, therefore, to calculate the corresponding stresses, it is necessary to set the boundary conditions.

On the lateral boundaries of the coal seam the following conditions can be set:

$$
\left.\sigma_{x x}\right|_{x= \pm l_{x}}=0,\left.\quad \sigma_{x z}\right|_{x= \pm l_{x}}=0 .
$$

In practice, at horizontal boundaries, the vertical stresses can be relatively accurately estimated through the pressure of the underlying rock on the coal steam (Farmer 1985), i.e., it is known

$$
\left.\sigma_{z z}\right|_{z= \pm l_{z}}=f(x)
$$

The conditions (6) and (7) are not enough for the solution of the differential equation (5). It is also necessary, for example, to specify the values of tangential stresses at horizontal boundaries. However, for various physical and practical reasons, this is not possible.

Velocity of pressure waves can be determined in some neighborhood of the middle of the coal seam. This velocity is related to the average stress (Nazarova et al. 2016):

$$
V_{p}(\sigma)=A-B e^{C \sigma} .
$$

Here $A, B$, and $C$ are constants defined from the experiment, $\sigma=1 / 2\left(\sigma_{x x}+\sigma_{z z}\right)$ is average stress. Since the coal seam can be considered thin $\left(l_{x} \gg l_{z}\right)$, it can be assumed that $\sigma_{z z}(x, z)=f(x)$. Thus, it can be assumed that the value $\sigma_{x x}(x, z)\left((x, z) \in\left[-l_{x}, l_{x}\right]\right.$ $\times[-a, a])$ is known.

In the works (Karchevsky 2017; Karchevsky et al. 2017), a two-step procedure was proposed for finding the horizontal, vertical, and tangential stresses in a coal seam. Based on the results (Nazarova et al. 2016), the following value was known:

$$
\left.\sigma_{x x}\right|_{z=0}=h(x), \quad x \in\left[-l_{x}, l_{x}\right] .
$$

Then on the first step the direct problem was set

$$
\begin{gathered}
\Delta^{2} \varphi=0, \\
\left.\frac{\partial^{2} \varphi}{\partial z^{2}}\right|_{z= \pm l_{z}}=f(x),\left.\frac{\partial^{2} \varphi}{\partial x \partial z}\right|_{z= \pm l_{z}}= \pm g(x),\left.\frac{\partial^{2} \varphi}{\partial x^{2}}\right|_{x= \pm l_{z}}=0,\left.\quad \frac{\partial^{2} \varphi}{\partial x \partial z}\right|_{x= \pm l_{x}}=0,
\end{gathered}
$$


for which the inverse problem was formulated: to find the unknown function $g(x)$, if additional information

$$
\left.\frac{\partial^{2} \varphi}{\partial z^{2}}\right|_{z=0}=h(x)
$$

is known for the solution of the direct problem (9).

At the second step, to find the function $\varphi$, the direct problem (9) is solving, in which all necessary boundary conditions are specified. Relations (4) allow us to obtain the values of horizontal, vertical and tangential stresses in the seam.

In this work, the following more "rich" additional information will be used that can provide the practical research of coal seam:

$$
\sigma_{x x}(x, z)=h(x, z), \quad(x, z) \in\left[-l_{x}, l_{x}\right] \times[-a, a] .
$$

where $0<a<l_{z}$, i.e., it can be assumed that $\sigma_{x x}$ is known not only in the middle of the seam, but also in some of its surroundings.

Let's consider the following function:

$$
s(x)=\frac{1}{2} \int_{-a}^{a} \sigma_{x x}(x, z) d z, \quad x \in\left[-l_{x}, l_{x}\right],
$$

Let's formulate a two-step procedure for determining horizontal, vertical and tangential stresses in the seam:

Step 1: Let's consider the direct problem (9) and formulate the inverse problem: to find the unknown function $g(x)$, if the following additional information

$$
s(x)-g(x)
$$

is known for the direct problem solution (9).

Step 2: Calculating the function $g(x)$, solving the direct problem (9), using the relations (4), the values of vertical, horizontal and tangential stresses in the seam can be obtained.

It should be noted, since the seam is immovable, thus the equality to zero of the moment of forces and the sum of the forces acting on the seam and the boundary conditions (6) and (7) entail the implementation of equality

$$
\int_{-l_{x}}^{l_{x}} g(x) d x=0
$$

(see Karchevsky 2017). 


\section{SOLUTION OF THE BIHARMONIC EQUATION AND EXPRESSION FOR STRESSES}

The solution of the direct problem (9) with an accuracy of a linear function of $x$ and $z$ can be represented as follows:

$$
\varphi(x, z)=f_{-2} \frac{x^{3}}{6}+f_{-1} \frac{x^{2}}{3}+g_{-1} x z\left(1-\frac{x^{2}}{3 l_{x}^{2}}\right)+\sum_{m=0}^{\infty} R_{m}(z) X_{m}\left(x ; l_{x}\right),
$$

where

$$
\begin{gathered}
R_{m}(z)=L_{m} \sin \left(\vartheta_{m} z\right) \operatorname{sh}\left(d_{m} z\right)+K_{m} \cos \left(\vartheta_{m} z\right) \operatorname{ch}\left(d_{m} z\right), \\
L_{m}=\frac{v_{m} \sin \left(v_{m} l_{z}\right) \operatorname{sh}\left(d_{m} l_{z}\right)-d_{m} \cos \left(v_{m} l_{z}\right) \operatorname{sh}\left(d_{m} l_{z}\right)}{v_{m} \operatorname{sh}\left(d_{m} l_{z}\right) \operatorname{ch}\left(d_{m} l_{z}\right)+d_{m} \sin \left(v_{m} l_{z}\right) \cos \left(v_{m} l_{z}\right)} f_{m} \\
-\frac{\cos \left(v_{m} l_{z}\right) \operatorname{ch}\left(d_{m} l_{z}\right)}{v_{m} \operatorname{sh}\left(d_{m} l_{z}\right) \operatorname{ch}\left(d_{m} l_{z}\right)+d_{m} \sin \left(v_{m} l_{z}\right) \cos \left(v_{m} l_{z}\right)} g_{m}, \\
K_{m}=\frac{v_{m} \cos \left(v_{m} l_{z}\right) \operatorname{sh}\left(d_{m} l_{z}\right)+d_{m} \sin \left(v_{m} l_{z}\right) \operatorname{ch}\left(d_{m} l_{z}\right)}{v_{m} \operatorname{sh}\left(d_{m} l_{z}\right) \operatorname{ch}\left(d_{m} l_{z}\right)+d_{m} \sin \left(v_{m} l_{z}\right) \cos \left(v_{m} l_{z}\right)} f_{m} \\
-\frac{\sin \left(v_{m} l_{z}\right) \operatorname{sh}\left(d_{m} l_{z}\right)}{v_{m} \operatorname{sh}\left(d_{m} l_{z}\right) \operatorname{ch}\left(d_{m} l_{z}\right)+d_{m} \sin \left(v_{m} l_{z}\right) \cos \left(v_{m} l_{z}\right)} g_{m}, \\
\vartheta_{m}=\operatorname{arctg} \sqrt{d_{m}^{4} / c_{m}^{4}-1}, c_{m}^{2}=\left\|X_{m}^{\prime}\left(\cdot ; l_{z}\right)\right\|^{2}, \quad d_{m}^{4}=\left\|X_{m}^{\prime \prime}\left(\cdot ; l_{z}\right)\right\|^{2},
\end{gathered}
$$

the values $f_{m}(m=-2,-1,0, \ldots)$ and $g_{m}(m=-1,0, \ldots)$ are the coefficients of the expansion of the functions $f(x)$ and $g(x)$ in a series of functions $X_{m}^{\prime \prime}\left(x ; l_{x}\right)$ and $X_{m}^{\prime}\left(x ; l_{x}\right)$ :

$$
f(x)=f_{-2} x+f_{-1}+\sum_{m=0}^{\infty} f_{m} X_{m}^{\prime \prime}\left(x ; l_{x}\right), \quad g(x)=g_{-1}\left(1-\frac{x^{2}}{l_{x}^{2}}\right)+\sum_{m=0}^{\infty} g_{m} X_{m}^{\prime}\left(x ; l_{x}\right),
$$

here $X_{m}(x ; l)=\frac{1}{\sqrt{l}} H_{m}(x / l), H_{m}(x)=\bar{P}_{m+4}^{4}(x)(m=0,1, \ldots), \bar{P}_{m+4}^{4}(x)$ - normed associated Legendre polynomials.

The procedure of expanding functions in a series in functions $X_{m}^{\prime \prime}\left(x ; l_{x}\right)$ or $X_{m}^{\prime}\left(x ; l_{x}\right)$ can be found in (Karchevsky 2016).

In our case, taking into account (14), $g_{-1}=0$. 
Among (4) and (11) for stresses we have the following expressions:

$$
\begin{gathered}
\sigma_{x x}(x, z)=\sum_{m=0}^{\infty} R_{m}^{\prime \prime}(z) X_{m}\left(x ; l_{x}\right) . \\
\sigma_{z z}(x, z)=f_{-2} x+f_{-1}+\sum_{m=0}^{\infty} R_{m}(z) X_{m}^{\prime \prime}\left(x ; l_{x}\right) \\
\sigma_{x z}(x, z)=-\sum_{m=0}^{\infty} R_{m}^{\prime}(z) X_{m}^{\prime}\left(x ; l_{x}\right)
\end{gathered}
$$

It easy to see that

$$
s(x)=\sum_{m=0}^{\infty} R_{m}^{\prime}(a) X_{m}\left(x ; l_{x}\right) .
$$

The functions $H_{m}(x)$ were introduced and investigated by S.A. Khalilov. Representations (16) was obtained in the works (Karchevsky 2016; Kudaibergenov et al. 2018) with the help of the following results (Khalilov 1977; 1978; 1982; 1984; Khalilov et al. 2010a; 2010b; 2011; 2014; 2015; Mintyuk 2007; Tkachenko 2014).

\section{NUMERICAL METHOD FOR SOLVING THE INVERSE PROBLEM}

The solution of the inverse problem (9), (10) can be found by minimizing the residual functional:

$$
J[g]=\int_{-l_{x}}^{l_{x}}[s(x ; g)-q(x)]^{2} d x,
$$

In order to emphasize the dependence on the function $g$, this function is indicated in the argument of the function $s(x)$.

The function $g(x)$ will be sought from the class of functions for which the relation (14) is hold. In this case, it is convenient to find it as a series:

$$
g(x)=\sum_{m=0}^{\infty} g_{m} X_{m}^{\prime}\left(x ; l_{x}\right)
$$

because

$$
\int_{-l_{x}}^{l_{x}} X_{m}^{\prime}\left(x ; l_{x}\right) d x=0 \quad(\forall m) .
$$


To minimize the residual functional (17), the conjugate gradient method can be used (see, for example, Polak 1971; Vasil'ev 1988):

$$
g^{k+1}=g^{k}-\alpha_{k} p_{k},
$$

where $k$ is the iteration number, $g^{0}$ is the initial approximation for the unknown function $g(x), p_{k}$ is the conjugate direction and

$$
p_{0}=J^{\prime}\left[g^{0}\right], \quad p_{k}=J^{\prime}\left[g^{k}\right]-\beta_{k} p_{k-1}, \quad \beta_{k}=-\frac{\left\|J^{\prime}\left[g^{k}\right]\right\|^{2}}{\left\|J^{\prime}\left[g^{k-1}\right]\right\|^{2}}, \quad k=1,2, \ldots,
$$

$\alpha_{k}$ parameter is the method step, which is a solution to the $1 \mathrm{D}$ problem of minimization

$$
\alpha_{k}=\arg \min _{\alpha} J\left[g^{k}-\alpha p_{k}\right] .
$$

Since the functional (17) can be considered as $J[g]=J\left[g_{0}, \ldots, g_{m}, \ldots\right]$, thus the following expression can be obtained for its gradient:

$$
J^{\prime}[g]=\left(j_{0}, \ldots, j_{m}, \ldots\right)^{T},
$$

from the relations (16) for the gradient component $j_{m}$ of the residual functional (17), the following expression is hold:

$$
j_{m}=\int_{-l_{x}}^{l_{x}} 2[s(x ; g)-q(x)] A_{m} X_{m}\left(x ; l_{x}\right) d x .
$$

where

$$
\begin{gathered}
A_{m}=\left(\hat{L}_{m} \vartheta_{m}+\hat{K}_{m} d_{m}\right) \cos \left(v_{m} a\right) \operatorname{sh}\left(d_{m} a\right)+\left(\hat{L}_{m} \vartheta_{m}-\hat{K}_{m} d_{m}\right) \sin \left(v_{m} a\right) \operatorname{ch}\left(d_{m} a\right), \\
\hat{L}_{m}=-\frac{\cos \left(v_{m} l_{z}\right) \operatorname{ch}\left(d_{m} l_{z}\right)}{v_{m} \operatorname{sh}\left(d_{m} l_{z}\right) \operatorname{ch}\left(d_{m} l_{z}\right)+d_{m} \sin \left(v_{m} l_{z}\right) \cos \left(v_{m} l_{z}\right)}, \\
\hat{K}_{m}=\frac{\sin \left(v_{m} l_{z}\right) \operatorname{sh}\left(d_{m} l_{z}\right)}{v_{m} \operatorname{sh}\left(d_{m} l_{z}\right) \operatorname{ch}\left(d_{m} l_{z}\right)+d_{m} \sin \left(v_{m} l_{z}\right) \cos \left(v_{m} l_{z}\right)} .
\end{gathered}
$$

We obtain the expression for the step of the method $\alpha_{k}$. By virtue of the linearity of the direct problem relatively to the searching function, we can write:

$$
\begin{aligned}
w(\alpha) & =\int_{-l_{x}}^{l_{x}}\left[s\left(x ; g^{k}-\alpha p_{k}\right)-q(x)\right]^{2} d x=\int_{-l_{x}}^{l_{x}}\left[s\left(x ; g^{k}\right)-q(x)-\alpha s\left(x ; p_{k}\right)\right]^{2} d x \\
& =J\left[g^{k}\right]-2 \alpha \int_{-l_{x}}^{l_{x}}\left[s\left(x ; g^{k}\right)-q(x)\right] s\left(x ; p_{k}\right) d x+\alpha^{2} \int_{-l_{x}}^{l_{x}} s^{2}\left(x ; p_{k}\right) d x,
\end{aligned}
$$


where the condition $w^{\prime}\left(\alpha_{k}\right)=0$, the step of the $\alpha_{k}$ method is easily calculated

$$
\alpha_{k}=\frac{\left\langle s\left(x ; g^{k}\right)-q(x), s\left(x ; p_{k}\right)\right\rangle}{\left\|s\left(x ; p_{k}\right)\right\|^{2}} .
$$

\section{PROPERTIES OF THE RESIDUAL FUNCTIONAL, EXISTENCE AND UNIQUENESS OF THE INVERSE PROBLEM SOLUTION}

The residual functional (17) is convex. Indeed, by virtue of the linearity of the direct problem (9), for example, we have

$$
s\left(x ; \gamma g_{1}+(1-\gamma) g_{2}\right)=\gamma s\left(x ; g_{1}\right)+(1-\gamma) s\left(x ; g_{2}\right) .
$$

Due to the property $L_{2}$-norms, we get

$$
\begin{gathered}
J\left[\gamma g_{1}+(1-\gamma) g_{2}\right]=\gamma J\left[g_{1}\right]+(1-\gamma) J\left[g_{2}\right]-\gamma(1-\gamma)\left\|s\left(x ; g_{1}\right)-s\left(x ; g_{2}\right)\right\|^{2} \\
\leq \gamma J\left[g_{1}\right]+(1-\gamma) J\left[g_{2}\right] .
\end{gathered}
$$

We assume that the data of the direct problem decomposed into finite series. This is the correct assumption for practice.

Denote $\delta s(x)=s\left(x ; g_{1}\right)-s\left(x ; g_{2}\right), \delta g(x)=g_{2}(x)-g_{1}(x)$ and

$$
\delta g(x)=\sum_{m=0}^{N} \delta g_{m} X_{m}^{\prime}\left(x ; l_{x}\right) .
$$

Evaluate

$$
\begin{aligned}
\int_{-l_{x}}^{l_{x}} \delta g^{2}(x) d x & =\int_{-l_{x}}^{l_{x}}\left(\sum_{m=0}^{N} \delta g_{m} X_{m}^{\prime}\left(x ; l_{x}\right)\right)^{2} d x \\
& =\sum_{m=0}^{N} \delta g_{m}^{2}\left\|X_{m}^{\prime}\right\|^{2}+\sum_{0 \leq m, k \leq N, k>m} 2 \delta g_{m} \delta g_{k} \int_{-l_{x}}^{l_{x}} X_{m}^{\prime}\left(x ; l_{x}\right) X_{k}^{\prime}\left(x ; l_{x}\right) d x .
\end{aligned}
$$

The functions $X_{m}^{j}\left(x ; l_{x}\right)$ are quasi-orthogonal (Khalilov 1977; 1978; Khalilov et al. 2010a), i.e.

$$
\frac{\left|\left\langle X_{m}^{j}, X_{k}^{j}\right\rangle\right|}{\left\|X_{m}^{j}\right\|\left\|X_{k}^{j}\right\|} \leq \theta, \quad \theta<<1, \quad j=1,2 .
$$

With this, the following inequality 


$$
\begin{aligned}
\int_{-l_{x}}^{l_{x}} \delta g^{2}(x) d x & \leq \sum_{m=0}^{N} \delta g_{m}^{2}\left\|X_{m}^{\prime}\right\|^{2}+\theta \sum_{0 \leq m, k \leq N, k>m} 2\left|\delta g_{m}\left\|\delta g_{k} \mid\right\| X_{m}^{\prime}\|\| X_{k}^{\prime} \|\right. \\
& \leq 1+N \theta \sum_{m=0}^{N} \delta g_{m}^{2}\left\|X_{m}^{\prime}\right\| \leq(1+N \theta)\left\|X_{N}^{\prime}\right\|^{2} \sum_{m=0}^{N} \delta g_{m}^{2}
\end{aligned}
$$

holds.

The last inequality holds because norm of functions $X_{m}^{\prime}\left(x ; l_{x}\right)$ grows monotonically with respect to the number $m$ (Khalilov 1977; 1978). Therefore, we get the estimate

$$
\sum_{m=0}^{N} \delta g_{m}^{2} \geq c_{1}\|\delta g\|^{2}, \quad c_{1}=\frac{1}{(1+N \theta)\left\|X_{N}^{\prime}\right\|^{2}} .
$$

Evaluate

$$
\begin{aligned}
& \int_{-l_{x}}^{l_{x}} \delta s^{2}(x) d x=\int_{-l_{x}}^{l_{x}}\left(\sum_{m=0}^{N} \delta g_{m} A_{m} X_{m}\left(x ; l_{x}\right)\right)^{2} d x \\
&=\sum_{m=0}^{N} \delta g_{m}^{2} A_{m}^{2}\left\|X_{m}\right\|^{2} \\
&+\sum_{0 \leq m, k \leq N, m>k} 2 \delta g_{m} \delta g_{k} A_{m} A_{k} \int_{-l_{x}}^{l_{x}} X_{m}\left(x ; l_{x}\right) X_{k}\left(x ; l_{x}\right) d x=\sum_{m=0}^{N} \delta g_{m}^{2} A_{m}^{2} .
\end{aligned}
$$

The last equality holds due to the orthogonality of the functions $X_{m}\left(x ; l_{x}\right)$. Therefore, we get the estimate

$$
\left\|\delta s^{2}\right\| \geq c_{2} \sum_{m=0}^{N} \delta g_{m}^{2}, \quad c_{2}=\min _{0 \leq m \leq N} A_{m}^{2} .
$$

From Eq. (18), (19) the criterion for the strong convexity of the residual functional (17) can be obtained:

$$
J\left[\gamma g_{1}+(1-\gamma) g_{2}\right] \leq \gamma J\left[g_{1}\right]+(1-\gamma) J\left[g_{2}\right]-\gamma(1-\gamma) \varkappa\left\|g_{1}-g_{2}\right\|^{2},
$$

where the parameter of strong convexity is $\varkappa=c_{2} / c_{1}$.

For correctness, it is necessary to require that the values $A_{m}$ for any numbers $m$ did not become zero. To do this, we must require for all $m=\overline{0, N}$ conditions

$$
A_{m} \neq 0=>\frac{v_{m}-d_{m} \operatorname{tg}\left(v_{m} l_{z}\right) \operatorname{th}\left(d_{m} l_{z}\right)}{v_{m}+d_{m} \operatorname{tg}\left(v_{m} l_{z}\right) \operatorname{th}\left(d_{m} l_{z}\right)} \neq \operatorname{tg}\left(v_{m} a\right) \operatorname{cth}\left(d_{m} a\right)
$$


Thus, it is proved:

Theorem: If the function $g(x)$ decomposes in a finite series in the functions $X_{m}^{\prime}(m)(m=\overline{0, N})$, and the constants a and $l_{z}$ are such as condition (20) is satisfied, then the residual functional (17) is strongly convex.

The strong convexity of the residual functional (17) implies the existence and uniqueness of its global minimum point, the convergence of the minimization process and the estimate of its convergence rate (see, for example, Polak 1971; Vasil'ev 1988), therefore, there are the existence and uniqueness of the solution of the inverse problem (9), (10).

The fulfillment of conditions (20) cannot be considered as burdensome, moreover, it is easily verified numerically for parameters $l_{z}, a$ and for all $m$ before solving the inverse problem. If (20) are not satisfied, then it is possible to change, for example, the parameter $a$ to its realization.

\section{NUMERAL EXAMPLE}

Testing of the proposed algorithm is carried out on simulated data, i.e. by solving the corresponding direct problem, the necessary values are calculated, after which a random error is added to the values of the functions playing the role of additional information, for example:

$$
\tilde{\sigma}_{x x}(x, z, g)=\sigma_{x x}(x, z, g)\left(1+\frac{P}{100} \xi(x, z)\right), \quad(x, z) \in\left[-l_{x}, l_{x}\right] \times[-a, a],
$$

here $P$ is the variable of percentage error, $\xi$ is a random variable normally distributed over the interval $[-1,1]$.

The linear dimensions of the coal seam: $l_{x}=30(\mathrm{~m}), l_{z}=1(\mathrm{~m})$.

We decompose the functions $f(x)$ and $g(x)$ in a series on functions $H_{m}^{\prime \prime}\left(x ; l_{x}\right)$ and $H_{m}^{\prime}\left(x ; l_{x}\right)$, taking $N$ terms of the series from the conditions

$$
\left\|f(x)-f_{-2} x-f_{-1}-\sum_{m=0}^{N} f_{m} X_{m}^{\prime \prime}\left(x ; l_{x}\right)\right\| \leq \varepsilon,\left\|g(x)-\sum_{m=0}^{N} g_{m} X_{m}^{\prime}\left(x ; l_{x}\right)\right\| \leq \varepsilon
$$

where $\varepsilon$ plays a small part as a known measurement error.

Select the initial approximation: $g_{0}=1, g_{m}=0(m=1, \ldots, N)$.

In the numerical example, we calculate the maximum shear stress

$$
\tau_{\max }(x, z)=\frac{1}{2} \sqrt{\left[\sigma_{x x}(x, z)-\sigma_{z z}(x, z)\right]^{2}+4 \sigma_{x z}^{2}(x, z)} .
$$


The value of $\tau_{\max }$ is a criterion for the possibility of rock bursts. If this value is greater than a certain value, then the probability of a rock bump is very high.

(a)

(b)

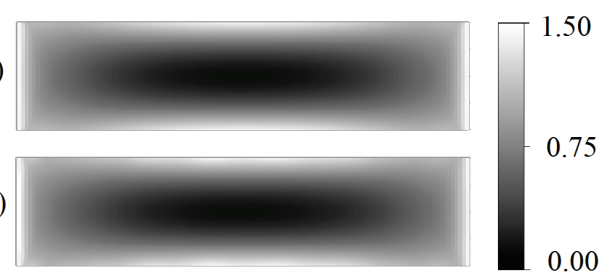

(c)

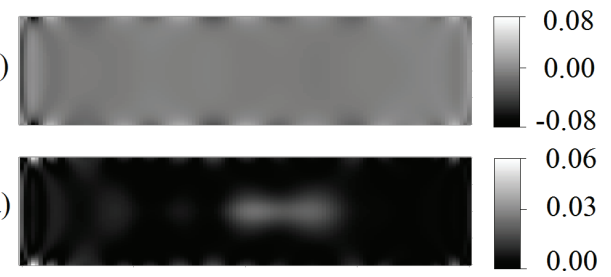

Fig. 2. Calculation results: (a) exact $\tau_{\max }(x, z)$, (b) calculated $\tau_{\max }(x, z)$ with a data error of $5 \%$, (c) absolute and (d) relative error during calculating $\tau_{\max }(x, z)$.

In Fig. 2. the results of calculating $\tau_{\max }(x, z)$ is presented. The calculations were carried out when the error in the data was $P=5 \%$.

As shown, the result of the calculations is satisfactory in accuracy: the maximum error does not exceed $6 \%$ with an error in the data of $5 \%$. The result of the calculations is consistent with the results of the works (Karchevsky 2017; Karchevsky et al. 2017), but the required values are calculated more accurately using additional information with an equal level of measurement errors.

\section{REMARK}

With the known information (11), another approach is possible. The following residual functional

$$
J[g]=\int_{-l_{x}}^{l_{x}} \int_{-a}^{a}\left[\sigma_{x x}(x, z ; g)-h(x, z)\right]^{2} d z d x,
$$

can be chosen. Its strong convexity can be proven.

Numerical experiments showed that to solve the problem posed, the residual functional (17) could be preferred to the residual functional (21).

The accuracy of recovery during using the functional (17) is insignificant, but higher. This can be explained by the fact that during integration see (13) the effect of measurement errors on the values of the function $s(x)$ may decrease. The number of iterations while minimizing the residual functional (21) to the desired value is less comparing with minimizing the functional (17), but calculating the functional (21) takes more time, just as the step $\alpha_{k}$ and the residual functional gradient require more time for calculations. Thus, the number of iterations is required more time for calculations in accordance with the minimization of the functional (17). 


\section{CONCLUSION}

The paper presents a possible way to calculate stresses in a coal seam enclosed between two drifts. It is known that in order to obtain vertical, horizontal and tangential stresses, it is necessary to calculate the Erie function that satisfies the biharmonic equation. It is necessary to specify boundary conditions. Vertical stresses at the upper and lower boundary of the coal seam are easily estimated, and tangential stresses cannot be determined with sufficient accuracy. It is proposed to use the kinematic data in the middle of the coal seam, and use these data as additional information to find the tangential stresses at the upper and lower boundary of the coal seam. After that, it is possible to correctly solve the biharmonic equation and obtain expressions for stresses. The proposed method is mathematically justified, numerical experiments are presented.

\section{REFERENCES}

ALEKSANDROV A.V., POTAPOV V.D., 1990, Fundamentals of the theory of elasticity and plasticity, Vyssh. Shk., Moscow.

BAKLASHOV I.V., 2005, Geomechanics. Vol. 1, Izd. MGGU, Moscow.

BEZUKHOV N.I., 1968, Fundamentals of the theory of elasticity, plasticity and creep, Vyssh. Shk., Moscow.

BULAT A.F., Zvyagil'skii, E.L., Lukinov V.V., Perepelitsa V.G., Pimonenko L.I. Shevelev G.A., 2008. Coal-bearing massif of Donbass as a heterogeneous medium. Kiev, Naukova dumka.

DJADKOV P.G., NAZAROV L.A., NAZAROVA L.A., 1997, Numerical modeling of the stressed state of the Earth's crust and conditions of dynamic instability of seismoactive faults during rifting, Geologiya i Geofizika, Vol. 38, No. 12, 2001-2010.

DOROKHOV D.V., SIVOKHIN V.I., KOSTYUK I.S., PODTYKALOV A.S., 1997, Technology underground mining of bedded deposits of minerals, DonGU, Donetsk.

FARMER I.W., 1985, Coal Mine Structures, Chapman and Hill, London.

JAEGER J.C., COOK N.G.W., ZIMMERMAN R.W., 2007, Fundamentals of Rock Mechanics, 4th ed., Wiley-Blackwell Publishing.

KARCHEVSKY A.L., 2016, Calculation of Stresses in a Coal Seam in Presence of Gas Diffusion, Journal of Applied and Industrial Mathematics, Vol. 10, No. 4, 482-493, https://doi.org/10.1134/ S1990478916040049

KARCHEVSKY A.L., 2017, Determination of the Possibility of Rock Burst in a Coal Seam, Journal of Applied and Industrial Mathematics, Vol. 11, No. 4, 527-534, https://doi.org/10.1134/S1990478917040019

KARCHEVSKY A.L., NAZAROVA L.A., ZAKHAROV V.N., NAZAROV L.A., 2017, Stress state estimation in coal bed under random conditions in contact zone with enclosing rocks based on inverse problem solution, Gornyi Zhurnal, Vol. 11, 37-40, https://doi.org/10.17580/gzh.2017.11

KISELYOV V.A., 1976, The plane problem of elasticity theory, Vyssh. Shk., Moscow.

KHALILOV S.A., 1977, About a System of Coordinate Functions for Solving Boundary Value Problems of Theory of Plates and Shells. In: Strength of Aircraft Structures, Vol. 4, Khar'kov. Aviats. Inst., Khar'kov, 60-65.

KHALILOV S.A., 1978, New Systems of Orthonormal Polynomials, Some Their Properties and Applications. In: Strength of Aircraft Structures, Vol. 5, Khar'kov. Aviats. Inst., Khar'kov, 46-56.

KHALILOV S.A., 1982, The solution in the rectangle static problems of the theory of elasticity given on the boundary stresses. In: Aircraft design issues, Vol. 3, Khar'kov. Aviats. Inst., Khar'kov, 120-127. 
KHALILOV S.A., 1984, Calculation of Some Definite Integrals Containing Associated Legendre Functions of the Second and Fourth Orders. In: Strength of Aircraft Structures, Vol. 7, Khar'kov. Aviats. Inst., Khar'kov, 158-165.

KHALILOV S.A., MINTYUK V.B., TKACHENKO D.A., 2010a, Construction and Investigation of the Approximate Analytical Solution of a Biharmonic Problem in aRectangle with Homogeneous Main Boundary Conditions, Aviats.-Kosmich. Tekhnika i Tekhnologiya, Vol. 2, 40-49.

KHALILOV S.A., MINTYUK V.B., TKACHENKO D.A., 2010b, An Approximate Analytic Solution of a Biharmonic Problem in the Rectangle with the Main Boundary Conditions Homogeneous on Two Opposite Sides and Arbitrary, on the Others, Aviats.-Kosmich. Tekhnika i Tekhnologiya, Vol. 5, 40-49.

KHALILOV S.A., MINTYUK V.B., TKACHENKO D.A., 2011, Construction and Investigation of an Analytical-Numerical Solution of the Problem on Bending a Rectangular Plate Rigidly Fixed, Otkrytye Inform. i Kompyut. Integrir. Tekhnologii, Vol. 49, 81-94.

KHALILOV S.A., MINTYUK V.B., TKACHENKO D.A., KOPYCHKO V.V., 2014, Spectrum of a Biharmonic Operator with Main Boundary Conditions in a Rectangle, Aviats.-Kosmich. Tekhnika i Tekhnologiya, Vol. 5, 70-78.

KHALILOV S.A., KRIVTSOV V.S., MINTYUK V.B., TKACHENKO D.A., 2015, The Green's Function of the Main Boundary Value Problem for the Biharmonic Operator in a Rectangle, Aviats.-Kosmich. Tekhnika i Tekhnologiya, Vol. 6, 12-22.

KUDAIBERGENOV M.K., KARCHEVSKY A.L., ISKAKOV K.T., 2018, Stress-strain state horizontal coal seam of finite length, Bulletin of the Karaganda University, Mathematics series, Vol. 2, 133-142.

LUXBACHER K., WESTMAN E., SWANSON P., KARFAKIS M., 2008, Three-Dimensional Time-Lapse Velocity Tomography of an Underground Longwall Panel, International Journal of Rock Mechanics and Mining Sciences, Vol. 45, No. 4, 478-485, https://doi.org/10.1016/j.ijrmms.2007.07.015

MINTYUK V.B., 2007, Orthonormal Basis of One-Dimensional Boundary Value Problems. Aviats.-Kosmich. Tekhnika i Tekhnologiya, Vol. 5, 32-36.

MIRONOV K.V., 1988, Directory of coal geologist, Nedra, Moscow.

Mountain Encyclopedia, 1991, Vol. 5, Soviet Encyclopedia, Moscow.

NAZAROV L.A., NAZAROVA L.A., YAROSLAVTSEV A.F., MIROSHNICHENKO N.A., VASIL'EVA E.V., 2011, Evolution of stress fields and induced seismicity in operating mines, Journal of Mining Science, Vol. 47, No. 6, 707-713, https://doi.org/10.1134/S1062739147060013

NAZAROV L.A., NAZAROVA L.A., KARCHEVSKY A.L., MIROSHNICHENKO N.A., 2013a, Pressure Distribution in a Hydrocarbon-Bearing Formation Based on the Daylight Surface Movement Measurements, Journal of Mining Science, Vol. 49, No. 6, 854-861. https://doi.org/10.1134/S1062739149060026

NAZAROV L.A., NAZAROVA L.A., KARCHEVSKII A.L., PANOV A.V., 2013b, Estimation of Stresses and Deformation Properties of Rock Masses which Is Based on the Solution of an Inverse Problem From the Measurement Data of the Free Surface Displacement, Journal of Applied and Industrial Mathematics, Vol. 7, No. 2, 234-240, https://doi.org/10.1134/S1990478913020130

NAZAROVA L.A., NAZAROV L.A., KARCHEVSKY A.L., VANDAMME M., 2014, Estimating diffusion-capacity parameters of a coal bed using the gas pressure measured in a hole and the solution of an inverse problem, Journal of Applied and Industrial Mathematics, Vol. 8, No. 2, 267-273, https:// doi.org/10.1134/S1990478914020136

NAZAROVA L.A., NAZAROV L.A., KARCHEVSKY A.L., VANDAMME M., 2015, Determining Kinetic Parameters of a Block Coal Bed Gas by Solving Inverse Problem Based on Data of Borehole Gas Measurements, Journal of Mining Science, Vol. 51, No. 4, 666-672, https://doi.org/10.1134/ S1062739115040027

NAZAROVA L.A., NAZAROV L.A., PROTASOV M.I., 2016, Reconstruction of $3 D$ stress field in coal-rock mass by solving inverse problem using tomography data, Journal of Mining Science, Vol. 52, No. 4, 623-631. https://doi.org/10.1134/S1062739116041010

NOWACKI V., 1970, Teoria sprężystości, Państowowe Wydawnictwo Naukowe, Warszawa.

POLAK E., 1971, Computational methods in optimization: a unified approach, Academic Press, New York. 
SHKURATNIK V.L., NIKOLENKO P.V., 2012, Methods for determining the stress-strain state of rock mass, Gornaya Kniga, Moscow.

SAMUL' V.A., 1982, Fundamentals of Elasticity and Plasticity Theory, Vyssh. Shk., Moscow.

TKACHENKO D.A., 2014, An Orthonormal Basis in the Energetic Space of a Biharmonic Operator in a Rectangle with the Homogeneous Main Boundary Conditions at the Border, Aviats.-Kosmich. Tekhnika i Tekhnologiya, Vol. 3, 41-51.

TURCHANINOV I.A., IOFIS V.A., KASPAR'YAN E.V., 1989, Fundamentals of rock mechanics, Nedra, Leningrad.

VASIL'EV F.P., 1988, Numerical Methods for Solving Extremal Problems, Nauka, Moscow.

ZAKHAROV V.N., MALINNIKOVA O.N., AVERIN A.P., 2016, Modeling mining-induced vibrations in production face area in coal-rock mass, Gornyi Zhurnal, Vol. 12, 28-32. https://doi.org/10.17580/ gzh.2016.12.06

ZAKHAROV V.N., 2002, Seismic-Acoustic Prediction and Control of the State and Properties of Rocks in Development of Coal Deposits, Inst. Gorn. Dela, Moscow. 